\title{
Técnicas avançadas de sensoriamento remoto aplicadas ao estudo de mudanças climáticas e ao funcionamento dos ecossistemas amazônicos.
}

Evlyn Márcia Leão de Moraes NOVO ${ }^{1}$; Laerte Guimaraes FERREIRA'2 Cláudio BARBOSA ${ }^{3}$; Claudio CARVALHO $^{4}$; Edson E. SANO ${ }^{5}$; Yosio SHIMABUKURO ${ }^{6}$; Alfreado HUETE ${ }^{7}$; Christopher POTTER ${ }^{8}$; Dar.A. ROBERTS ${ }^{9}$; Laura L. HESS ${ }^{9}$; John J. MELACK ${ }^{9}$; Hiroki YOSHIOKA ${ }^{10}$; Steven KLOOSTER ${ }^{11}$; Vipin KUMAR ${ }^{12}$; Ranga MYNENI ${ }^{13}$; Piyachat RATANA ${ }^{14}$; Kamel DIDAN ${ }^{14}$; Tomoaki MIURA ${ }^{15}$.

\section{RESUMO \\ Este artigo se propõe a apresentar exemplos de questões científicas que puderam ser respondidas no contexto do Projeto LBA (Large Sale Biosphere-Atmosphere Experiment in Amazonia) graças à contribuição de informações derivadas de sensoriamento remoto. Os métodos de sensoriamento remoto permitem integrar informações sobre os vários processos físicos e biológicos em diferentes escalas de tempo e espaço. Nesse artigo, são enfatizados aqueles avanços de conhecimento que jamais seriam alcançados sem a concorrência da informação derivada de sensoriamento.}

PALAVRAS - CHAVE

Sensoriamento remoto, padrões, processos.

\section{Advanced remote sensing techniques for global changes and Amazon ecosystem functioning studies.}

\begin{abstract}
This paper aims to assess the contribution of remote sensing technology in addressing key questions raised by the Large Scale Biosphere-Atmosphere Experiment in Amazonia (LBA). The answers to these questions foster the knowledge on the climatic, biogechemical and hydrologic functioning of the Amazon, as well as on the impact of human activities at regional and global scales. Remote sensing methods allow integrating information on several processes at different temporal and spatial scales. By doing so, it is possible to perceive hidden relations among processes and structures, enhancing their teleconnections. Key advances in the remote sensing science are summarized in this article, which is particularly focused on information that would not be possible to be retrieved without the concurrence of this technology.
\end{abstract}

\section{KEYWORDS}

Remote sensing, pattern, processes.

\footnotetext{
${ }^{1}$ Divisão de Sensoriamento Remoto, Instituto Nacional de Pesquisas Espaciais, São José dos Campos, SP, Brasil, evlyn@ltid.inpe.br

${ }^{2}$ Universidade Federal de Goiás, Instituto de Estudos Sócio-Ambientais, Goiânia, Brasil

${ }^{3}$ Divisão de Processamento de Imagens, Instituto Nacional de Pesquisas Espaciais, São José dos Campos, SP

${ }^{4}$ Embrapa-CPATU, Belém, PA

${ }^{5}$ Embrapa Cerrados, Brasilia, DF.

${ }^{6}$ Divisão de Sensoriamento Remoto, Instituto Nacional de Pesquisas Espaciais-INPE

${ }^{7}$ University of Arizona, Tucson, Arizona 85721 USA

${ }^{8}$ NASA Ames Research Center, Moffet Field, CA USA

${ }^{9}$ University of California at Santa Barbara, Santa Barbara, CA 93106-4060

${ }^{10}$ Meijo University, Gifu 509-0251 Japan

${ }^{11}$ California State University / NASA ARC, Moffett Field, CA, USA

${ }^{12}$ University of Minnesota, Mineapolis, MN, USA

${ }^{13}$ Boston University, Boston, MA 02215 USA

${ }^{14}$ University of Arizona, Tucson, Arizona 85721 USA

${ }^{15}$ University of Arizona, Tucson, Arizona 85721 USA, presently at University of Hawaii, Honolulu, HI 96822
} 


\section{ACTA \\ AMAZONICA}

TÉCNICAS AVANÇADAS DE SENSORIAMENTO REMOTO APLICADAS AO ESTUDO DE MUDANÇAS CLIMÁTICAS E AO FUNCIONAMENTO DOS ECOSSISTEMAS AMAZÔNICOS.

\section{INTRODUÇÃO}

Esse artigo apresenta um panorama dos principais avanços concretos que o uso da tecnologia de sensoriamento remoto trouxe ao conhecimento dos ecossistemas da região Amazônica, de suas interações com o clima em diferentes escalas espaciais e temporais, e de suas respostas e adaptações à crescente alteração imposta pelas atividades humanas na região.

Existem inúmeros projetos desenvolvidos no âmbito do LBA que utilizam a tecnologia de sensoriamento remoto em maior ou menor grau, e para os quais esta ferramenta é bastante relevante. Contudo, a questão chave endereçada nesse artigo diz respeito à ampliação de conhecimento sobre o funcionamento da região Amazônica que somente pode ser alcançada em decorrência de avanços nos métodos de extração de informações de imagens de sensores remotos, e na ciência e tecnologia de sensoriamento remoto como um todo.

Neste sentido, para este artigo foram selecionados alguns exemplos de avanços cujo mérito foi documentar processos e interações que se revelam em escalas espaciais e temporais passíveis de registro apenas por sensores remotos. O primeiro exemplo mostra o uso de imagens de radar de abertura sintética (SAR) combinados a imagens de sensores passivos de microondas para mapear a variação no tempo e no espaço da área ocupada pêlos diferentes habitas dos ecossistemas alagáveis da região Amazônica. Até recentemente, o papel dos ecossistemas alagáveis no balanço global de carbono para a bacia Amazônica vinha sendo negligenciado. A partir da disponibilidade de dados que permitiram mapear as variações sazonais da área alagada, bem como determinar os tipos de cobertura dominantes em diferentes fases do ciclo hidrológico pode-se confirmar o papel chave desses ambientes no balanço de carbono da região Amazônica, e ampliar o escopo das pesquisas de pequena escala. É nesse contexto que se propôs na segunda fase do LBA-ECO o estudo das ligações entre a cobertura vegetal dos ambientes alagáveis e a dinâmica do carbono.

O segundo exemplo ilustra o papel dos produtos biofísicos desenvolvidos no âmbito do Sistema de Observação da Terra (Earth Observing System) no estudo das relações entre a cobertura vegetal e processos globais tais como oscilações do El Ñino. O uso destes produtos é também abordado no terceiro exemplo, no qual uma série de produtos do sensor MODIS/ Terra é apresentada e suas contribuições à ampliação do conhecimento sobre a dinâmica da cobertura vegetal, sua fenologia, estrutura e diversidade são discutidas.

O quarto exemplo enfatiza a utilização dos índices de vegetação MODIS (produto MOD13) na identificação de padrões sub regionais, ligados a processos de média escala. Por fim, o quinto exemplo representa a contribuição que a busca de padronização de métodos de extração de informações tem trazido à integração de dados provenientes de diferentes sensores, com especificações distintas de resoluções espaciais, espectrais e radiométricas. A padronização proposta preconiza a análise de mistura como a ferramenta que permite transpor o domínio do sinal radiométrico para o do sinal biofísico. Para ilustrar sua proposta, Roberts (2002) apresenta os resultados de sua aplicação no estudo das modificações de uso e cobertura na região Amazônica ao longo de 25 anos, integrando dados adquiridos pelo sensor MSS (Mustispectral Scanner System) a bordo dos quatro primeiros satélites da série Landsat, com dados do sensor TM (Thematic Mapper) a bordo dos Landsat- 4 e 5 .

\section{MAPEAMENTO DE ECOSSISTEMAS ALAGÁVEIS POR MEIO DE INTEGRAÇÃO DE SENSORES DE MÚLTIPLAS RESO̧LU- ÇÕES E EM MÚLTIPLAS DATAS.}

Uma das grandes contribuições da tecnologia de sensoriamento remoto no âmbito do projeto LBA foi a de ampliar o conhecimento sobre o papel desempenhado pelos ecossistemas alagáveis no balanço global de carbono. Embora estudos anteriores tivessem alertado para a importância dos fluxos de carbono entre os rios e as planícies (Richey et al., 1990, Melack e Forsberg, 2001), apenas recentemente foi possível estimar sua contribuição quanto à evasão de $\mathrm{CO}^{2}$ para a atmosfera (Richey et al., 2002). Para que esse fluxo pudesse ser estimado, faltavam informações básicas como a extensão e condições de cobertura de ecossistemas alagáveis e sua variação sazonal.

Para contornar essa limitação os autores utilizaram dados derivados de sensoriamento remoto e puderam quantificar, pela primeira vez, a superfície alagada em duas épocas (baixa e alta vazão) para uma área de amostragem de 1,77 milhões de quilômetros quadrados daAmazônia Central Brasileira. Os padrões sazonais de inundação derivados de imagens de sensores passivos de micro-ondas (Sippel et al., 1998) foram incorporados às informações extraídas de um mapa de ecossistemas sistemas alagáveis gerado a partir de imagens de um sistema de radar de abertura sintética (Hesse t al., 2003) e medidas "in situ" de $\mathrm{CO}_{2}$ para computar o fluxo total para área de amostragem.

Os pressupostos teóricos e os procedimentos utilizados para esses cálculos bem como os erros a eles associados encontram-se discutidos em Richey et al. (2002). Não obstante os graus de incerteza associados às medidas de fluxo de $\mathrm{CO}_{2}$ decorrentes da extrema diversidade dos ecossistemas amazônicos, os resultados apresentados pelos autores sugerem que os sistemas alagáveis podem ser responsáveis por uma fração considerável do carbono não computado nos balanços globais (missing carbon), se as medidas obtidas nesse estudo puderem ser extrapoladas para toda a faixa tropical do planeta.

O uso de dados de sensoriamento remoto para melhorar a quantificação dos fluxos de carbono, entretanto, só foi possível porque houve um consistente e constante investimento em pesquisa de novas abordagens. Os dados utilizados por Richey et al. (2002) basearam-se na utilização de imagens de um radar de abertura sintética (Sythetic Aperture Radar - SAR), a bordo do satélite japonês JERS-1 (Japanese Earth Research Satellite), operando na banda L. As características geométricas e radiométricas desses dados encontram-se descritas em Chapman et al. (2002).

Essas imagens puderam ser utilizadas porque estudos anteriores (Hess et al., 1990; Hess et al., 1995) haviam demonstrado que o pulso de micro-ondas nessa região do espectro penetra suficientemente a cobertura vegetal de tal 


\section{ACTA \\ AMAZONICA}

TÉCNICAS AVANÇADAS DE SENSORIAMENTO REMOTO APLICADAS AO ESTUDO DE MUDANÇAS CLIMÁTICAS E AO FUNCIONAMENTO DOS ECOSSISTEMAS AMAZÔNICOS. forma que ao ser refletido especularmente pela superfície da água, interage com a vegetação inundada provocando um fenômeno conhecido por reflexão de canto. Essa reflexão aumenta a intensidade da energia retroespalhada por esses ecossistemas, o que permite o seu mapeamento. Esse processo de realce da vegetação alagada em imagens de radar pode ser compreendido a partir da observação da Figura 1. Nessa Figura pode-se observar uma subcena de uma imagem JERS-1, Banda $\mathrm{L}$, adquirida durante o período de enchente. Devido ao efeito de reflexão de canto, as regiões de floresta inundada permitem que uma maior quantidade de energia seja refletida de volta para o sensor, o que torna possível mapear os vales alagados, os quais se apresentam em tonalidade cinza clara, em contraste com a tonalidade cinza escura da Floresta de Terra Firme.

A método desenvolvido para esse mapeamento encontrase descrito em Hess et al. (2003). O mapeamento foi realizado utilizando-se os mosaicos SAR de toda a bacia Amazônica construídos para duas fases do ciclo hidrológico (Rosenquvist et al. 2000), os períodos de níveis de água baixa e de níveis de água alta. Uma completa avaliação sobre a representatividade das imagens adquiridas em 1995 (baixa) e 1996 (alta) pode ser encontrada em Hess et al., 2003. Os autores concluem que os dados utilizados no estudo são representativos da média histórica das cheias da região, enquanto que os mosaicos do período de baixa representam condições mais extremas, com níveis bem mais baixos do que a média histórica.

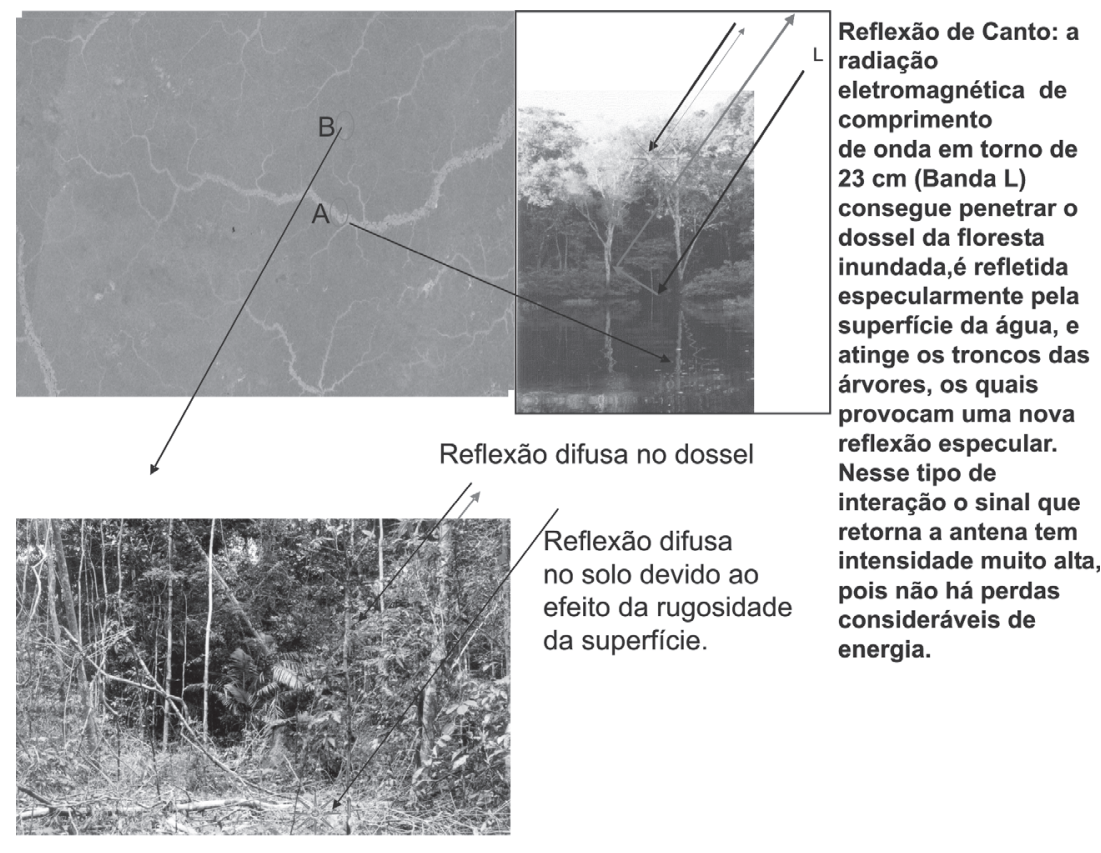

Figura 1 - Interação da Radiação de Microondas com as Florestas Inundáveis (A) e com a Floresta de Terra Firme, e as diferenças de tonalidade (cinza claro versus cinza escuro) que produzem na imagem obtida pelo sensor ativo de microondas que opera na Banda L, e se encontrava a bordo do satélite JERS-1 responsável pela a aquisição de imagens sobre a região Amazônica em duas fazes do ciclo hidrológico (vazante - 1995, enchente- 1996).
O primeiro passo no mapeamento dos ecossistemas inundáveis foi a criação de uma máscara que permitisse isolálos dos ecossistemas de terra-firme. Para isso, os autores definiram como inundáveis todas as áreas que estivessem inundadas em ambas as fases do ciclo hidrológico, bem como áreas que não se apresentassem inundadas naquelas datas, mas apresentassem contigüidade com áreas inundadas e feições geomorfológicas visivelmente compatíveis com sistemas inundáveis. A criação da máscara permitiu o cálculo da área total inundada bem como a remoção dos ecossistemas terrestres da análise reduzindo a possibilidade de mistura de habitats de terra firme com características de retroespalhamento semelhantes às das áreas inundadas. $\mathrm{O}$ procedimento para a delimitação dos ecossistemas inundáveis (Barbosa et al., 2000) foi realizado no Sistema de Processamento de Imagens Georreferenciadas (SPRING), aplicativo gratuito desenvolvido pelo Instituto Nacional de Pesquisas Espaciais (INPE) e que permite a integração de dados de várias fontes e formatos (Câmara, 1996).

Após a delimitação da área de inundação, procedeu-se à classificação do que Hess et al. (2003) chamaram de classes de "estado da cobertura vegetal" (cover state classes) nas duas fases do ciclo hidrológico. Essas classes consistem em um entre cinco tipos de cobertura definidos pela fitofisionomia (sem vegetação; vegetação herbácea, vegetação arbustiva; vegetação arbórea; floresta). A combinação dessas cinco classes com as condições de inundação (inundado e não-inundado) dão origem as seguintes classes: Água; ambientes não inundados sem cobertura vegetal (fundo de lagos, bancos de areias, bancos lamosos) e com cobertura vegetal herbácea; ambientes inundados com vegetação herbácea predominante; ambientes não inundados, com vegetação arbustiva, ambientes inundados com vegetação arbustiva; ambientes inundados, com ocorrência de bosques esparsos, ambientes não inundados com dominância de Floresta, Ambientes Inundados, com predominância de Floresta.

A classificação dos "estados da cobertura" foi realizada utilizando-se um tipo de classificador que leva em conta a informação de cada pixel (unidade de registro da energia proveniente de uma dada região da imagem). Esse classificador foi aplicado às imagens referentes às duas datas: vazante e enchente. Essa mudança de abordagem foi necessária visto que a escala de variação espacial dos habitats presentes nas áreas alagáveis requeria um algoritmo capaz de capturar feições mais finas.

Um aspecto importante no mapeamento dos ecossistemas alagáveis 


\section{ACTA \\ AMAZONICA}

TÉCNICAS AVANÇADAS DE SENSORIAMENTO REMOTO APLICADAS AO ESTUDO DE MUDANÇAS CLIMÁTICAS E AO FUNCIONAMENTO DOS ECOSSISTEMAS AMAZÔNICOS. foi, também, a criação de um sistema que permitisse avaliar a precisão do mapa gerado. Para isso foram realizadas quatro campanhas de videografia analógica e digital em toda região, as quais permitiram criar um conjunto de dados de referência para a classificação dos sistemas alagáveis, bem como para avaliar a consistência do método utilizado. As estratégias adotadas no desenvolvimento desse sistema de suporte à validação do mapeamento, bem como seus resultados encontram-se descritos em Hess et al. (2002).

Os resultados desse estudo permitiram estimar as modificações dos "estados das classes de cobertura da terra" em duas condições extremas do ciclo hidrológico: nível baixo da água e nível alto da água (Figura 2).

Os gráficos da Figura 3 permitem verificar que na área de estudo o tipo de cobertura dominante durante o período imageado é o de Floresta, ocupando 53 \% da área total. Durante o período de cheia, as águas vão inundar a Floresta a qual sozinha passa a representar quase a metade da área. Ambientes tais como "água aberta" por exemplo, apresentaram, proporcionalmente, pequena flutuação em área entre os dois períodos, embora, em termos absolutos, dadas ás dimensões da região Amazônica, essa variação corresponda a oito mil km², ou seja, uma área cerca de $50 \%$ maior do que a do Distrito Federal. Uma cobertura também bastante dinâmica é formada pelas áreas de solo exposto e campos não inundados que são ocupados durante o período
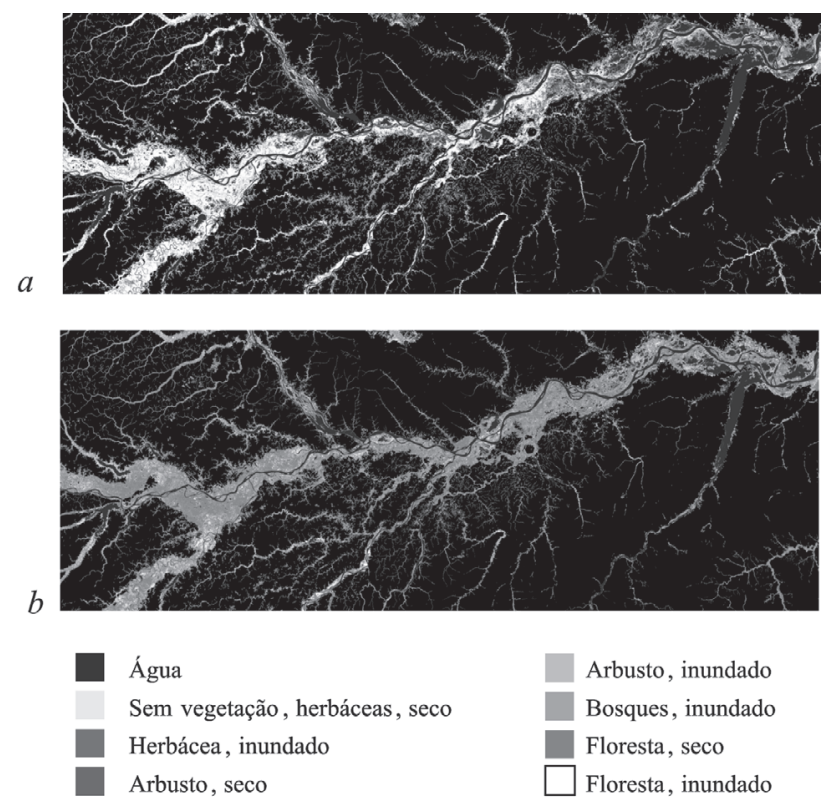

Figura 2 - Mapeamento da vegetação de áreas alagáveis e da inundação ao longo do canal principal do Solimões-Amazonas entre Coari e Santarém. a) nível alto da água(Maio-Junho, 1996); b) nível baixo da água (Setembro- Outubro de 1995). Modificação principal da cobetura do solo de floresta no alto curso, próximo a Coari para superfície livre da água em direção a Santarém. Fonte: Hess et al., 2003. de inundação por água aberta ou por plantas flutuantes. $\mathrm{O}$ conhecimento dessa dinâmica é fundamental para os estudos realizados por Melack et al. (2003) visando à determinação dos fluxos de $\mathrm{CH}_{4}$ dos ecossistemas alagáveis da Amazônia, uma vez que trabalhos anteriores (Devol $\boldsymbol{e t}$ al., 1990) já demonstraram a interferência dos diferentes tipos de cobertura sobre a magnitude das emissões.

\section{APLICAÇÃO DE DADOS DE SATÉLITES NO ESTUDO DAS TELECONEXÕES ENTRE OS PROCESSOS DOS ECOSSISTEMAS AMA- ZÔNICOS E O CLIMA GLOBAL.}

A avaliação e o monitoramento dos padrões temporais e espaciais da vegetação são de grande importância para os estudos sobre a variabilidade dos ecossistemas, para a compreensão das ligações entre suas estruturas e funções e a variabilidade climática incluindo aqueles processos ligados às mudanças no uso e cobertura da terra.

Diversos estudos (ex. Potter et al., 2002) têm demonstrado a utilidade das informações regionais derivadas de satélites para o entendimento das teleconexões entre o clima global e os processos que respondem pelo funcionamento dos ecossistemas amazônicos. O termo teleconexão é usado em estudos meteorológicos para descrever variações simultâneas no clima e em processos a ele relacionados em regióes muito distantes entre si.

A influência dos padrões da superfície oceânica, tais como a oscilação do El Niño (El Niño-Southern Oscilation - ENSO) sobre a circulação atmosférica e sobre o clima da superfície terrestre é considerada, por exemplo, uma teleconexão global bastante significativa.

Nesse contexto, é de grande interesse para o conjunto de questões do LBA-ECO investigar as teleconexões do clima regional em relação às medidas mensais da fração de radiação fotossinteticamente ativa absorvida pela vegetação (FAPAR) derivada de dados de sensores remotos. Como demonstrado por Potter et al., 2002, os dados de FAPAR representam uma medida biofísica que permite distinguir os diferentes dosséis em termos de sua capacidade de atenuação da luz, sendo assim uma variável de entrada de grande relevância nos modelos de troca de energia, água, carbono e gases traços entre a biosfera e atmosfera terrestre.

Para isso, foi proposta uma série de índices de oscilação clima-oceano, os quais se dividem em:

- Índice de Oscilação Sul (Southern Oscillation Index SOI), que representa a diferença padronizada entre a pressão ao nível do mar (sea level pressure) na latitude de $17^{\circ} \mathrm{S}$, longitude de $149^{\circ} \mathrm{W}$ e na latitude de $13^{\circ} \mathrm{S}$, longitude de $131^{\circ} \mathrm{E}$.

- Índice NIÑO1+2 - derivado da diferença de temperatura de superfície (sea surface temperature-SST) entre 0-10' $\mathrm{S}$ e $90^{\circ} \mathrm{W}-80^{\circ} \mathrm{W}$ no pacífico tropical.

- Índice de Oscilação Ártica (Artic Oscillation Index-AO), determinado pela anomalia de $1000 \mathrm{mb}$ ao norte de $20^{\circ} \mathrm{N}$. 


\section{ACTA AMAZONICA}

TÉCNICAS AVANÇADAS DE SENSORIAMENTO REMOTO APLICADAS AO ESTUDO DE MUDANÇAS CLIMÁTICAS E AO FUNCIONAMENTO DOS ECOSSISTEMAS AMAZÔNICOS.
A partir da análise de dados de FAPAR derivados do sensor AVHRR-NOAA para o período compreendido entre 1982 e 1999 foi possível constatar que as anomalias nos valores de FAPAR na região a oeste de $60^{\circ}$ de longitude está inversamente correlacionada com o chamado Índice de Oscilação Sul (South Oscilation Index - SOI). A correlação entre a magnitude das anomalias e SOI é negativa a oeste de 60 graus, mas positiva na região a leste de 60 graus (Figura 3). Além disso, as anomalias de FAPAR observadas na Amazônia também apresentam ligações com o Índice de Oscilação do Atlântico Norte (NAO). Estas teleconexões têm profundas conseqüências para o ciclo de carbono da região Amazônica, sendo para isso fundamental a existência de produtos biofísicos que permitam o seu monitoramento numa freqüência compatível com as oscilações dos padrões de circulação oceânica e atmosférica.

Esses estudos permitiram concluir que as medidas de FAPAR derivadas de imagens de satélite são fortemente conectadas aos eventos ENSO em toda a região Amazônica. A identificação dessas conexões só tornou-se mensurável devido à disponibilidade de dados do Sensor AVHRR-NOAA num longo período de observação. Um estudo dessa natureza, entretanto, só foi possível devido à existência de séries históricas de dados de satélite, a partir dos quais foi possível calcular os valores de FAPAR. Da mesma forma, também foi possível concluir que as variações interanuais nos valores de FAPAR na região centro sul da Amazônia, além de associadas às anomalias de precipitação, estão fortemente relacionadas à monção de verão da América do Sul e indiretamente às variações no $\mathrm{AO}$.

Os estudos realizados por Potter et al. (2000) representam, portanto, um exemplo seminal de conhecimento que pode apenas ser alcançado com a contribuição direta da tecnologia de sensoriamento remoto. Estudos semelhantes dificilmente poderiam ser realizados a partir da aquisição sobre a FPAR in situ, uma vez que avaliação da hipótese de teleconexão requer um grande volume de dados adquiridos ao longo de vários anos, sobre vastas regiões.

\section{AVALIAÇÃO DA DINÂMICA SAZONAL DA BACIA AMAZÔNICA ATRAVÉS DA ANÁLISE DE PRODUTOS BIOFÍSICOS DO SENSOR MODIS/TERRA.}

A disponibilidade de produtos biofísicos gerados pelo Moderate Resolution Imaging Spectroradiometer Sensor (MODIS), a bordo dos satélites Terra eAcqua do programa espacial americano de observação da Terra (Earth Observing System EOS), oferece uma oportunidade única de caracterizar as condições da superfície terrestre e a dinâmica da cobertura vegetal da Amazônia. Esses produtos foram recentemente validados e encontram-se disponíveis em resoluções espaciais que variam de $250 \mathrm{~m}$ a $1 \mathrm{~km}$, com uma freqüência diária, semanal ou bimensal. A Tabela 1 resume o conjunto de produtos gerados a partir das diferentes combinações de bandas do sensor MODIS.

Adisponibilidade de produtos biofísicos representa um grande avanço nas aplicações de sensoriamento remoto à modelagem dos processos ambientais, e de certa forma, resume o conhecimento acumulado em décadas de pesquisas que se estendem desde as aplicações iniciais de dados do sensor AVHRR/ NOAA no estudo das relações entre as oscilações climáticas de grande escala e as variações sazonais da cobertura vegetal do planeta.

Os dados MODIS representam um grande avanço nos estudos que envolvem o monitoramento da cobertura vegetal, pois apresentam desempenho radiométrico equivalente ao de um sensor de alta resolução espacial, com a vantagem adicional da elevada taxa de revisita.
Vazão Alta

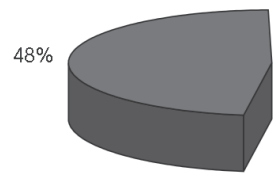

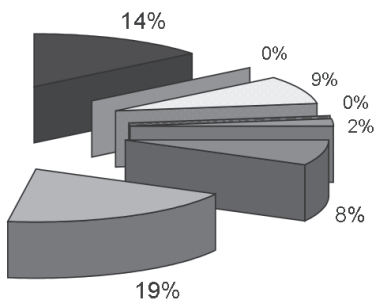

Vazão Baixa

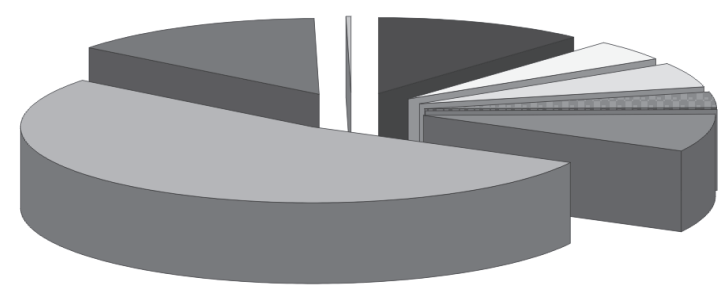

\footnotetext{
口Água Livre

口Campinas e arbustos - seco

口Florestas - seco
}

$\begin{array}{ll}\square \text { Solo Exposto/campo } & \square \text { Campos inundáveis e plantas aquáticas emersas } \\ \square \text { Campinas e arbustos - inundado } & \square \text { Savanas inundadas } \\ \square \text { Florestas - (inundado sazonal ou permanentemente) } & \square \text { Coberturas Mistas }\end{array}$

Figura 3 - Distribuição espacial de estados da cobertura de ecossistemas alagáveis, derivada de imagens JERS-1, obtidas em duas fases do ciclo hidrológico: nível de água alto e nível de água baixo (Fonte: Hess et al., 2003). 
Tabela 1 - Produtos do Sensor MODIS a bordo dos satélites Terra e Acqua.

- (fonte: <<http://modis.gsfc.nasa.gov/data/summary.html >)

\begin{tabular}{|c|c|c|}
\hline Nome do Produto & MOD \# & Descrição \\
\hline Radiância & MOD 01 & Essa imagem é o dado base para gerar os demais produtos \\
\hline $\begin{array}{l}\text { Radiância Calibrada e } \\
\text { Georreferenciada }\end{array}$ & MOD 02 & Imagem já submetida à calibração radiométrica e geométrica. \\
\hline $\begin{array}{l}\text { Dados para } \\
\text { Georreferenciamento }\end{array}$ & MOD 03 & Coordenadas geodésicas, ângulos de iluminação e de visada. \\
\hline Aerosol & MOD 04 & $\begin{array}{l}\text { Imagem com a distribuição espacial da espessura óptica, tipo } \\
\text { e tamanho dos aerosois sobre a superfície da Terra. }\end{array}$ \\
\hline $\begin{array}{l}\text { Água Total Precipitável } \\
\text { (Método Infravermelho) }\end{array}$ & MOD 05 & $\begin{array}{l}\text { Essa imagem fornece informação sobre a distribuição espacial } \\
\text { da quantidade de vapor d água sobre a superfície da Terra. }\end{array}$ \\
\hline Nuvens & MOD 06 & $\begin{array}{l}\text { Esse produto fornece informações sobre as propriedades das } \\
\text { nuvens (fase, temperatura do topo, altura). }\end{array}$ \\
\hline Perfis Atmosféricos & MOD 07 & Perfil de ozônio total, umidade, temperatura, vapor d'água. \\
\hline $\begin{array}{l}\text { Atmosfera } \\
\text { georeferenciado, nível } 3\end{array}$ & MOD 08 & $\begin{array}{l}\text { Estatísticas sobre propriedades atmosféricas, em } \\
\text { escala diária, semanal, mensal. }\end{array}$ \\
\hline Reflectância & MOD 09 & $\begin{array}{l}\text { Reflectância ao nível da superfície nas bandas 1, 2, 3, 4, 5, 6, e } 7 \text { (centradas em } 648 \\
\text { nm, } 858 \mathrm{~nm}, 470 \mathrm{~nm}, 555 \mathrm{~nm}, 1240 \mathrm{~nm}, 1640 \mathrm{~nm}, \text { e2130 nm, respectivamente). }\end{array}$ \\
\hline Neve & MOD 10 & Distribuição global de neve, mapeada com freqüência diária, semanal. \\
\hline $\begin{array}{l}\text { Temperatura e } \\
\text { emissividade. }\end{array}$ & MOD 11 & stribuição da emissividade e temperatura da superfície terrestre. \\
\hline $\begin{array}{l}\text { Uso e Cobertura e } \\
\text { Mudanças de Uso da Terra }\end{array}$ & MOD 12 & Mapas com 17 categorias de Uso da Terra conforme classificação definida pelo IGBP. \\
\hline Índices de Vegetação & MOD 13 & $\begin{array}{l}\text { Mapas de índices de vegetação mostrando variações temporais } \\
\text { e espaciais na cobertura vegetal com freqüência semanal, quinzenal e mensal. }\end{array}$ \\
\hline Anomalias Termais & MOD 14 & $\begin{array}{c}\text { Esse produto inclui ocorrência de incêndios (dia e noite), localização dos } \\
\text { focos, energia produzida para cada foco de incêndio. O produto também inclui } \\
\text { mapas semanais, mensais, resumos das co-orrências de incêndio diários, semanais, } \\
\text { mensais por tipo de incêndio e anomalias termais. }\end{array}$ \\
\hline $\begin{array}{l}\text { Índice de Área Foliar and } \\
\text { Fração de Radiação } \\
\text { Fotossinteticamente } \\
\text { Ativa Absorvida pela } \\
\text { Vegetação. }\end{array}$ & MOD 15 & $\begin{array}{l}\text { Esse produto fornece um mapa com a distribuição especial do } \\
\text { índice de Área Foliar e da Fração de Radiação Fotossinteticamente Ativa } \\
\text { Absorvida pela Vegetação com freqüência diária e semanal. }\end{array}$ \\
\hline Evapotranspiração & MOD 16 & $\begin{array}{l}\text { Esse produto fornece a distribuição de resistência superficial informa } \\
\text { sobre os limites de umidade para a fotossíntese e transpiração. } \\
\text { Fornece também a distribuiçãa da Evaporatranspiração. }\end{array}$ \\
\hline $\begin{array}{l}\text { Produção Primária e } \\
\text { Fotossíntese }\end{array}$ & MOD 17 & $\begin{array}{l}\text { Mapas com a distribuição semanal e anual da } \\
\text { Fotossíntese Líquida, Produção Primária Bruta. }\end{array}$ \\
\hline $\begin{array}{l}\text { Radiância emergente da } \\
\text { água, normalizada }\end{array}$ & MOD 18 & $\begin{array}{l}\text { Radiância emergente das superfícies oceânicas em } 7 \text { faixas } \\
\text { espectrais (Banda } 8 \text { a 14, } 412 \mathrm{~nm} \text { a } 681 \mathrm{~nm} \text { ). }\end{array}$ \\
\hline $\begin{array}{l}\text { Concentração de } \\
\text { Pigmento }\end{array}$ & MOD 19 & $\begin{array}{l}\text { Mapa com a concentração diária, semanal, mensal e anual de partículas em águas do } \\
\text { Caso 1, com propriedades ópticas dominadas pela clorofila e pigmentos associados. }\end{array}$ \\
\hline $\begin{array}{l}\text { Clorofila Il e } \\
\text { Fluorescência }\end{array}$ & MOD 20 & $\begin{array}{l}\text { Mapa com da descrição diária, semanal, mensal e anual das propriedades da } \\
\text { fluorescência da clorofila: altura do pico de emissão, eficiência da emissão. }\end{array}$ \\
\hline $\begin{array}{l}\text { Concentração } \\
\text { de Clorofila a }\end{array}$ & MOD 21 & $\begin{array}{c}\text { Mapa com a distribuição diária, semanal, mensal ,e anual. O produto também } \\
\text { disponibiliza coeficientes de absorção da água, fitoplâncton, detritos e carbono } \\
\text { orgânico dissolvido. }\end{array}$ \\
\hline
\end{tabular}




\section{ACTA AMAZONICA}

continuação da tabela 1

\begin{tabular}{|c|c|c|}
\hline Nome do Produto & MOD \# & Descrição \\
\hline $\begin{array}{l}\text { Radiação Fotossinte- } \\
\text { ticamente Ativa }\end{array}$ & MOD 22 & $\begin{array}{l}\text { Esse produto fornece a distribuição espacial de quatro parâmetros: } \\
\text { Irradiância solar em todas as bandas de interesse oceanográfico, } \\
\text { a Irradância instantânea da Radiação Fotossinteticamente Ativa } \\
\text { imediatamente abaixo da superfície, a Irradiância média diária. }\end{array}$ \\
\hline $\begin{array}{l}\text { Concentração de Sólidos } \\
\text { em Suspensão na Água }\end{array}$ & MOD 23 & $\begin{array}{l}\text { Mapa com a distribuição de concentração de partículas em suspensão } \\
\text { nas águas do Caso 1, dominadas por Clorofila e seus detritos associados. }\end{array}$ \\
\hline $\begin{array}{l}\text { Concentração } \\
\text { de Matéria Orgânica }\end{array}$ & MOD 24 & $\begin{array}{l}\text { Mapa com a distribuição diária, bi-semanal, semanal, mensal e anual. } \\
\text { da Concentração de Matéria Orgânica em Suspensão Particulada e Dissolvida. }\end{array}$ \\
\hline Concentração de Cocolith & MOD 25 & $\begin{array}{l}\text { Mapas diários, semanais, mensais e anuais da concentração de coccoliths } \\
\text { nos seguintes formatos: numero/ } \mathrm{m}^{3} \text {; concentração de calcita em mg-CaCO3/mª } \\
\text { concentração de pigmento na biomassa dos coccolitóforos. }\end{array}$ \\
\hline $\begin{array}{l}\text { Coeficiente de Atenuação } \\
\text { da Água do Mar }\end{array}$ & MOD 26 & $\begin{array}{l}\text { Mapas diários, semanais, mensais e anuais do } \\
\text { Coeficiente de Atenuação das águas oceânicas em } 590 \text { nm e } 530 \text { nm. }\end{array}$ \\
\hline $\begin{array}{l}\text { Produtividade Primária do } \\
\text { Oceano }\end{array}$ & MOD 27 & Mapa semanal da Produtividade Primária do Oceano. \\
\hline $\begin{array}{l}\text { Temperatura da } \\
\text { Superfície do Mar }\end{array}$ & MOD 28 & $\begin{array}{l}\text { Mapa da temperatura da superfície oceânica em escala global. Médias diárias diurnas e } \\
\text { noturnas da temperatura dos oceanos, bem como dados diários. Médias diárias, } \\
\text { semanais, mensais e anuais das temperaturas noturnas e diurnas também são fornecidas. }\end{array}$ \\
\hline Gelo oceânico & MOD 29 & Mapa diário e semanal da cobertura de gelo dos oceanos. \\
\hline $\begin{array}{l}\text { Perfis de Temperatura e } \\
\text { Umidade }\end{array}$ & MOD 30 & \\
\hline $\begin{array}{l}\text { Concentração de } \\
\text { Ficoeritrina }\end{array}$ & MOD 31 & $\begin{array}{l}\text { Mapa com a concentração de um dos pigmentos algais mais comuns } \\
\text { em águas oceânicas. Três parâmetros são fornecidos: Concentração, Composição, } \\
\text { Constituintes oticamente ativos. Esses parâmetros são fornecidos com freqüêencia diária, } \\
\text { bi-semanal, semanal , mensal e anualmente. }\end{array}$ \\
\hline Máscara d e Nuvens & MOD 35 & Máscara diária de nuvens com informações sobre as sombras de nuvens. \\
\hline $\begin{array}{l}\text { Coeficiente de } \\
\text { Absorção Total }\end{array}$ & MOD 36 & $\begin{array}{l}\text { Mapa com o coeficiente de absorção total da água. } \\
\text { Válido apenas para cenas com céu limpo. }\end{array}$ \\
\hline $\begin{array}{l}\text { Propriedades de Aerossóis } \\
\text { Oceânicos }\end{array}$ & MOD 37 & $\begin{array}{l}\text { Mapas diários, semanais, mensais e anuais da } \\
\text { distribuição espacial das propriedades dos aerossóis oceânicos }\end{array}$ \\
\hline Epislon de Águas Claras & MOD 39 & $\begin{array}{l}\text { Esse produto representa a razão entre a radiância em } 531 \text { nm e } \\
667 \mathrm{~nm} \text { a qual está associada a conteúdo de ferro presente no aerossol } \\
\text { de águas claras. Fornece estimativas diárias, semanais, mensais e anuais. }\end{array}$ \\
\hline Albedo (16 dias) & MOD 43 & $\begin{array}{l}\text { Esse produto fornece a função da reflectância bidirecional para cada pixel das bandas } \\
\text { do produto MOD09, e os valores de albedo derivados para cada uma das bandas e } \\
\text { integrados em três bandas amplas (0.4-0.7, 0.7-3.0, e } 0.4-3.0 \text { mícron). }\end{array}$ \\
\hline $\begin{array}{l}\text { Conversão da } \\
\text { Cobertura Vegetal }\end{array}$ & MOD 44 & $\begin{array}{l}\text { Mapas com a distribuição espacial de áreas com modificações da } \\
\text { cobertura vegetal a intervalos de } 3 \text { meses, bem como um mapa } \\
\text { síntese anual com as mudanças globais da cobertura vegetal. }\end{array}$ \\
\hline
\end{tabular}

Para as aplicações terrestres, os produtos MODIS disponíveis incluem imagens com medidas de reflectância da supefície em 7 bandas distribuídas do visível ao infravermelho médio (Vermote et al., 2002). Essas imagens foram submetidas à correção para remoção de nuvens e de efeitos de aerosóis, ozônio, e espalhamento Rayleigh (correção atmosférica). Os demais produtos foram desenvolvidos com o objetivo de fornecer parâmetros consistentes para a comparação das condições da superfície terrestre no tocante às mudanças de cobertura, atividade fotossintética e produção primária induzidas pela ocupação humana ou por mudanças climáticas
(Running et al., 1994; Justice et al., 1998). Por isso, todos eles são gerados a partir de imagens corrigidas geométrica e radiometricamente.

Dentre os produtos biofísicos disponíveis para uso imediato destacam-se os índices de vegetação. Os índices de vegetação são medidas radiométricas adimensionais que envolvem a combinação de bandas espectrais. O mais tradicional índice de vegetação é o da diferença normalizada entre a radiação vermelha e infravermelha (NDVI) e tem sido amplamente utilizado para o monitoramento da vegetação. $\mathrm{O}$ NDVI é um índice que permite monitorar, em grande escala, o 


\section{ACTA \\ AMAZONICA}

TÉCNICAS AVANÇADAS DE SENSORIAMENTO REMOTO APLICADAS AO ESTUDO DE MUDANÇAS CLIMÁTICAS E AO FUNCIONAMENTO DOS ECOSSISTEMAS AMAZÔNICOS. "vigor" da vegetação, porque quanto mais exuberante a vegetação menor é a porcentagem de radiação vermelha refletida por ela. Por outro lado, quanto maior o vigor da vegetação maior a porcentagem de radiação infravermelha refletida. O NDVI, entretanto é bastante sensível às características do substrato da vegetação, e para contornar esse efeito indesejável, uma série de novos índices forma propostos (Huete et al. 2002a). Existem numerosos trabalhos que associam as variações de precipitação aos valores de NDVI como indicador do vigor da vegetação. Os valores de NDVI tendem a aumentar em anos chuvosos, com o aumento da densidade e vigor da vegetação, diminuindo consideravelmente em anos secos. Um estudo (Gurgel, 2000) sobre as conexões entre o Índice de Vegetação por Diferença Normalizada (NDVI) e as variabilidades climáticas anual e interanual sobre o Brasil permitiu a identificação de sete grandes tipos de cobertura vegetal e revelou sua variabilidade anual e interanual e o lapso de reação dos diferentes bioma à precipitação. A aplicação de técnicas de Análise por Componentes Principais (ACP) aos valores de NDVI demonstrou a importância da disponibilidade de dados orbitais com resolução espacial moderada, mas, alta freqüência temporal para a diferenciação das grandes feições da vegetação do território brasileiro. Os altos valores de correlações obtidos entre os autovetores, resultantes da ACP da Radiação de Ondas Longas (ROL) e do NDVI, que correspondem aos modos verão/inverno $(r=0,91)$ e primavera/ outono $(r=0,70)$, indicaram que a variabilidade anual da cobertura vegetal brasileira é modulada em grande parte pelo regime climático.

O NDVI é um índice bastante útil principalmente em regiões em que a vegetaçãoé suficientemente estável para permitir avaliações de mudanças inter anuais. Por se tratar de uma razão entre bandas, o NDVI tem a vantagem de corrigir efeitos decorrentes do processo de imageamento (iluminação, relevo, atenuação atmosférica).

Ele é, entretanto, bastante afetado pela variação nas propriedades dos solos. Esse efeito se tornou mais perceptível

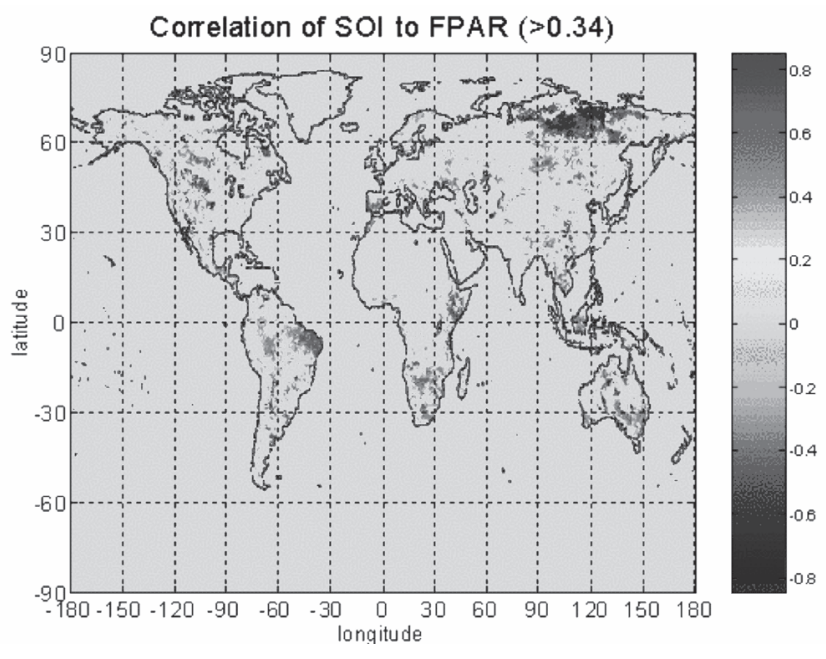

Figura 4 - Correlação entre SOI e FAPAR (Fonte: Potter et al., 2002) com o uso de sensores com melhor resolução radiométrica e espectral. Em decorrência do impacto do solo sobre os valores do NDVI propôs-se o EVI (Enhanced Vegetation Index -Índice de Vegetação Melhorado) com o objetivo de reduzir o efeito do substrato. Na Figura 5 pode-se observar a variação sazonal do EVI na América do Sul. Pode-se observar que mesmo em escala regional, existem claras diferenças nos valores de EVI entre o período seco e úmido, notadamente na área relativa ao arco do desflorestamento. Essas imagens também mostram claramente a transição entre o Cerrado e a Floresta, principalmente durante a estação seca.

Os perfis sazonais do índice EVI derivados de dados MODIS revelaram padrões sazonais bem definidos nas áreas de cerrado, mas demonstraram que esse sinal tende a se enfraquecer na medida que se avança para a região de transição para a floresta, próximo a Santana do Araguaia (Figura 6). Os perfis temporais de EVI também revelaram diferenças importantes no sinal de sazonalidade para os diferentes tipos de cobertura: Floresta, Cerrado e Pastagem.

Outro produto disponível, mas ainda não amplamente utilizado é o IAF (Índice de Área Foliar) ou LAI (Leaf Área Index). O IAF representa a razão entre a área ocupada pelas folhas de planta e a área do terreno disponível para seu cultivo. Esse índice é muito utilizado em modelos de produtividade primária visto que a fotossíntese é realizada pelas folhas. Ao longo das últimas décadas existe uma extensa bibliografia que confirma a alta correlação entre diferentes índices de vegetação e o IAF em diferentes tipos de cultivos e biomas.

Estudos preliminares demonstraram a habilidade do IAF discernir diferenças internas na cobertura florestal da Amazônia ampliando a perspectiva de pesquisas in situ que permitam determinar os fatores controles de tal variabilidade (Myneni $e t$ al., 2002). As imagens de Produção Primária Líquida (NPP) também são fundamentais à compreensão do ciclo do carbono na bacia Amazônica (Potter et al., 2001). As avaliações preliminares dos produtos MODIS para a região Amazônica

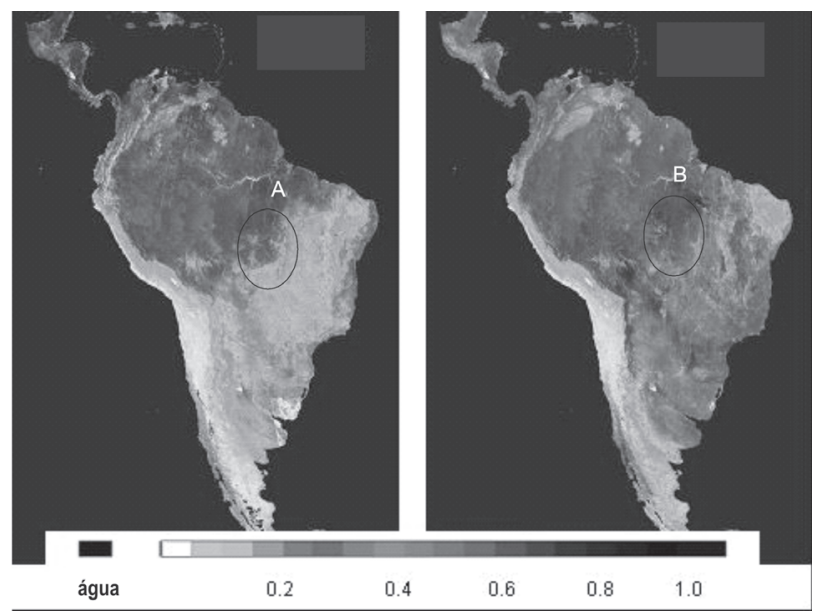

Figura 5 - Índice de vegetação realçado (EVI) derivado de dados MODIS para a estação seca (esquerda) e úmida (direita) (http:/ /tbrs.arizona.edu) 


\section{ACTA \\ AMAZONICA}

indicam claramente sua superioridade sobre os produtos de sensoriamento remoto disponíveis anteriormente, pois permitem avaliar as características dinâmicas da cobertura vegetal, revelar seus ritmos fenológicos e suas conexões com outros sistemas ambientais.

\section{MONITORAMENTO DA DINÂMICA ES- PAÇO-TEMPORAL DAS FISIONOMIAS DO CERRADO BRASILEIRO COM O USO DE ÍNDICES DE VEGETAÇÃO}

O Cerrado Brasileiro, o segundo mais importante bioma na América do Sul, é formado por um complexo mosaico de fisionomias, as quais resultam da combinação, em diferentes proporções, dos estratos gramineo-lenhoso, arbustivo e arborescente. O Cerrado Brasileiro tem sido objeto de rápidas transformações, sendo hoje considerado um dos 25 hotspots mundiais (Myers et al., 2000). Estima-se que aproximadamente $40 \%$ da sua cobertura original já tenham sido convertidos, principalmente para pastagens cultivadas (Sano et al., 2001; Mantovani e Pereira, 1998). O Cerrado pode ser entendido como parte de um gradiente ambiental e de perturbações antrópicas, limitado a noroeste pela floresta úmida, e a sudeste pelos campos gramíneos e formações savânicas mais secas. Assim, e no contexto da região Amazônica, é de fundamental importância entender a dinâmica espaço-temporal do Cerrado, bem como o seu potencial para influenciar os balanços regionais de energia, água e carbono.

Além da importância do Cerrado como um bioma a ser conhecido para que possa ser utilizado de modo sustentável, sua dinâmica de ocupação também afeta a região amazônica em diversos aspectos. Um dos aspectos mais críticos é a dinâmica das queimadas. Numerosos estudos demonstram que a freqüência e duração das queimadas afetam a estrutura da vegetação de Cerrado, aumentando a proporção de espécies herbáceas, muito mais sujeitas a estresse hídrico durante anos secos, o que favorece a ocorrência de íncêndios. O mais recente caso de incêndio florestal ocorrido a partir da propagação de fogo na região do cerrado ocorreu no estado de Roraima entre 01 de dezembro de 1997 e 31 de março de 1998. Acondição de extrema seca devidoao fenômeno El Niño (CPTEC, 2005) agravou o quadro de queimadas normalmente verificadas naquela região nos meses de janeiro e fevereiro, fazendo com que o fogo saísse fora de controle, gerando um incêndio florestal somente extinto com o início das chuvas, em 31 de março de 1998 (Shimabukuro et al., 1999).

Relatórios preliminares produzidos pelas equipes de combate ao fogo, por especialistas do Ministério do Meio Ambiente, dos Recursos Hídricos e da Amazônia Legal (MMA) e por pesquisadores da região (Barbosa, 1998) indicaram que o incêndio florestal em Roraima afetara grandes extensões de diferentes sistemas naturais, já submetidos ao fogo em anos anteriores (como os cerrados e áreas de desflorestamentos antigos e recentes) ou nunca anteriormente atingidos. Os primeiros incêndios tiveram o seu início tradicional em áreas de cerrado, já no final do mês de agosto de 1997 (fim do período úmido), segundo os moradores da região (Santos, 1998) e dados do sensor AVHRR (Advanced Very High Resolution Radiometer) do satélite NOAA (National Oceanic and Atmospheric Administration) (Barbosa, 1998). Estes incêndios se estenderam para áreas de floresta a partir de março, de acordo com o relatório da Brigada de Infantaria da Selva.

O incêndio florestal de Roraima ocorreu numa região com características similares àquelas encontradas no chamado arco de desflorestamento (Negreiros et al., 1996), ou seja, na região limite entre as formações savânicas e florestais de Roraima. A região de floresta afetada pelo incêndio reúne condições favoráveis para que o uso do fogo, como prática agrícola, se transforme em incêndio florestal, a saber: (1) é uma área sujeita a elevado grau de interferência antrópica (estradas e assentamentos rurais na floresta); e (2) possui um regime de chuvas representado por dois períodos bem distintos: período úmido, com totais mensais de $150 \mathrm{~mm}$ a $350 \mathrm{~mm}$ entre abril e agosto, e período seco, caracterizado por precipitações mensais inferiores a 50 mm e elevada deficiência hídrica no solo.

Apesar da grande importância estratégica do Cerrado em decorrência do grande apelo que oferece para agricultura intensiva, por sua susceptibilidade ao fogo, por seu caráter de transição para a Floresta, existem poucos esforços no sentido da utilização de dados de sensoriamento remoto não só para o seu monitoramento sistemático (Skole et al., 1994), mas também para ampliar o conhecimento sobre sua tipologia, estrutura e resposta fenológica às variáveis climáticas.
Figura 6 - Exemplo de uma perfil sazonal mostrando tipos de cobertura natural e convertidas em pastagens e agricultura na região de transição entre a Floresta e o Cerrado entre as cidades de Santana do Araguaia (PA) e Canguçu (TO) (Fonte: Huete et al., 2002). 


\section{ACTA \\ AMAZONICA}

TÉCNICAS AVANÇADAS DE SENSORIAMENTO REMOTO APLICADAS AO ESTUDO DE MUDANÇAS CLIMÁTICAS E AO FUNCIONAMENTO DOS ECOSSISTEMAS AMAZÔNICOS,
Num esforço para preencher essa lacuna Ferreira et al., (2000) realizaram a caracterização radiométrica e biofísica dos principais tipos de cobertura natural encontrados no Cerrado. Tal estudo teve por base duas campanhas de campo realizadas nos períodos seco e chuvoso (2000) no Parque Nacional de Brasília (PNB), uma significativa e representativa área do bioma Cerrado.

Durante estas campanhas, dados biofísicos de campo (ex. $\%$ de cobertura verde, índice de área foliar, etc) e dados aerotransportados (imagens digitais RGB e perfis espectroradiométricos) foram coletados em cinco das principais fisionomias encontradas na área do PNB (i.e. Campo Limpo, Campo Sujo, Campo Cerrado, Cerrado Strictu Sensu e Mata de Galeria).

A partir destes dados, foi possível avaliar a eficiência dos índices de vegetação disponibilizados pelo sensor MODIS, bem como determinar: a) a sensibilidade desses índices às características estruturais e fisionômicas do Cerrado e os processos ecológicos a elas associados; b) a eficiência de novos sensores (ex. MODIS) e algorítmos (ex. índice de vegetação realçado-EVI) para o monitoramento da cobertura vegetativa do Cerrado; c) a resposta dos índices de vegetação à dinâmica sazonal da paisagem.

Em relação à discriminação das fisionomias do Cerrado, Ferreira et al., (Ferreira, 2003 a) constataram o melhor desempenho do índice NDVI comparativamente ao $\mathrm{EVI}^{1}$. Este resultado pode ser atribuído principalmente a maior dependência do NDVI à refletância no vermelho, a qual, por outro lado, parece ser a principal responsável pela discriminação dos tipos de cobertura do Cerrado. Como a reflectância na região do vermelho aumenta com a redução da biomassa, havendo um aumento de sua transmitância, o NDVI é também afetado pelas propriedades de reflectância do substrato. O EVI tem menor poder de discriminação entre os tipos devido à

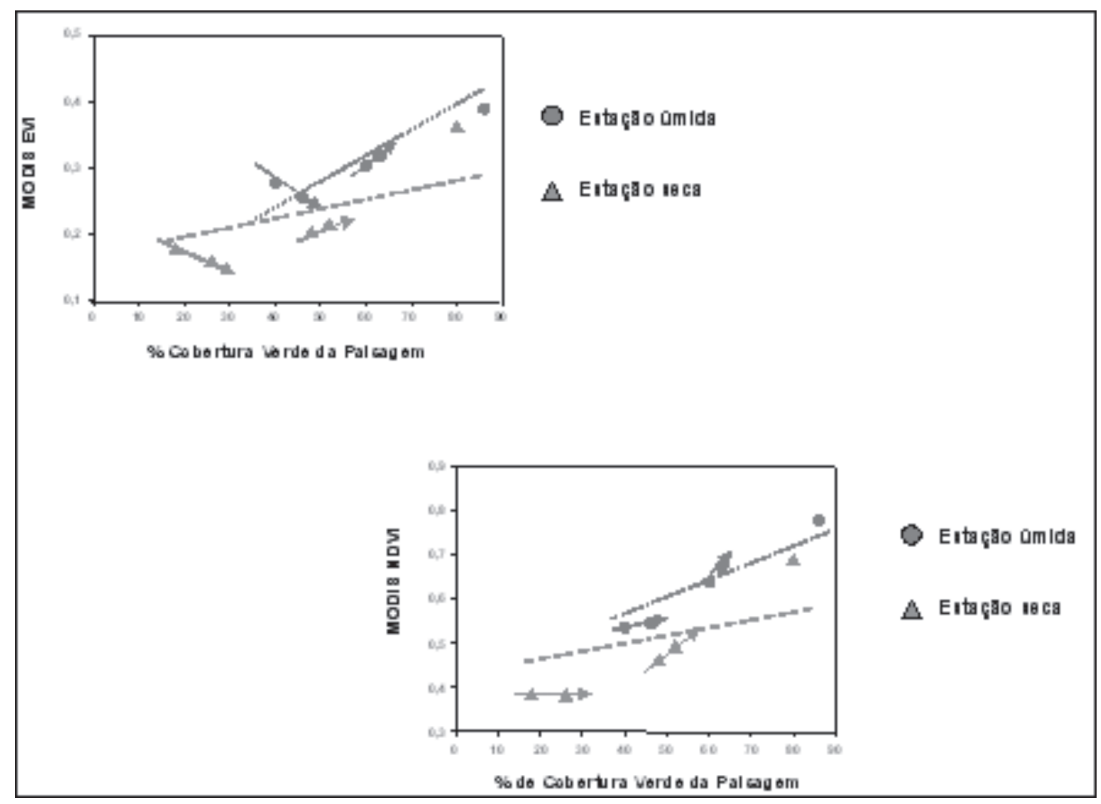

Figura 7 - Relações biofísicas entre a porcentagem (\%) de cobertura verde medida "in situ" e índices de vegetação derivados das imagens EVI e NDVI. maior variância que este apresenta dentro de uma mesma classe. Esta maior variabilidade na resposta do EVI pode significar maior correlação com os parâmetros biofísicos da vegetação, independente das propriedades espectrais dos solos.

Em relação à dinâmica sazonal da paisagem (Ferreira et al. , 2004) constataram que as várias fisionomias de Cerrado podem ser agrupadas em três domínios principais (i.e. gramíneolenhoso, arbustivo e arborescente), com diferenças sazonais na porcentagem de cobertura verde as quais decrescem do Campo Limpo (54\%) para a Mata de Galeria (6\%). Por outro lado, para esses mesmos domínios fisionômicos, os índices simulados NDVI e EVI mostraram variações entre 29 e $12 \%$ e entre 36 e $8 \%$, respectivamente.

Neste estudo também foram observadas correlações significativas entre diferentes medidas "in situ" de propriedades da vegetação fotossinteticamente ativa (porcentagem de cobertura verde na escala da paisagem), e índices derivados de imagens tais como o NDVI e o EVI. Entretanto, parece que há influências secundárias significantes a partir das quais as relações biofísicas da estação seca diferem das relações observadas para a estação chuvosa (Figura 7). Da mesma forma, pode-se observar que as relações biofísicas apresentam distintas inclinações, em função do domínio fitofisionômico analisado (i.e. gramíneo, arbustivo ou arborescente). Certamente, estudos fisionômicos adicionais, associados a modelos de transferência radiativa, são necessários para caracterizar a influência das características fisionômicas (estruturais) da cobertura vegetal sobre essas correlações.

A comparação entre os dados simulados MODIS com dados simulados ETM+ indicou uma maior sensibilidade dos índices de vegetação ETM+ às variações sazonais da vegetação, o que foi atribuído à maior proximidade entre as bandas vermelho e infravermelho próximo observada para o sensor ETM+. Por outro lado, comparativamente ao MODIS NDVI, o NDVI derivado dos dados simulados AVHRR é significativamente menos sensível às mudanças sazonais, o que é principalmente devido à baixa resolução espectral das bandas vermelho e infravermelho do sensor AVHRR, o que, por sua vez, ocasiona uma redução no contraste e sensibilidade destas bandas às diferenças na vegetação (Figura 8) .

As distintas funcionalidades e habilidades associadas ao NDVI e EVI claramente sugerem um potencial sinergismo entre estes dois índices para o monitoramento operacional da cobertura vegetal no bioma Cerrado. Especificamente, o EVI mostrou maior sensibilidade na detecção de mudanças sazonais entre as varias formações de Cerrado, enquanto o NDVI apresentou melhor desempenho na discriminação destas formações. Os resultados 


\section{ACTA AMAZONICA}

confirmam que os índices de vegetação são sensíveis não apenas à biomassa verde, mas também às características fitofisionômicas da vegetação de Cerrado e permitem melhorar a capacidade de monitorar suas mudanças interanuais e sazonais.

Os resultados de Ferreira et al., (Ferreira, 2003) vêm atender aos requisitos dos vários modelos disponíveis para a predição dos impactos das atividades humanas sobre os fluxos de água, carbono, nitrogênio. $\mathrm{O}$ aumento da capacidade de predição desses modelos (NASA-CASA, Century, SiB2, por exemplo) depende de um melhor conhecimento da variabilidade espacial dos fatores que controlam essas variáveis na Amazônia em função de características específicas não só do ambiente natural (solo, topografia, precipitação, temperatura, entre outros) como também dos modos de apropriação econômica da terra (tipo de cultura, práticas culturais, adequação à legislação ambiental, etc.). O modelo CASA-NASA, por exemplo, tem se modificado ao longo do tempo de modo a introduzir imagens mensais de NDVI para estimar modificações da cobertura do solo pela vegetação (Potter et al, 1993; Potter et al. 1999; Potter et al., 2001). Tem também introduzido mudanças que permitam incorporar informações sobre os diferentes padrões de transição entre diferentes sistemas agrícolas e de conversão da cobertura vegetal original em pastagens e culturas agrícolas.

\section{PADRONIZAÇÃO DO MAPEAMENTO DE USO E COBERTURA DA TERRA EM SU- PORTE AO LBA.}

Existe um grau de incerteza bastante grande sobre as conseqüências da interferência antrópica na Amazônia a médio e longo prazo. Algumas informações importantes, tais como as taxas de desflorestamento, as taxas de abandono das terras desflorestadas, a estrutura de idades e área ocupada pela vegetação natural em diferentes fases de regeneração, a área de floresta sujeita a degradação em decorrência do corte seletivo, o grau de fragmentação da floresta, a área sujeita a queimadas ainda não se encontram disponíveis para a Amazônia como um

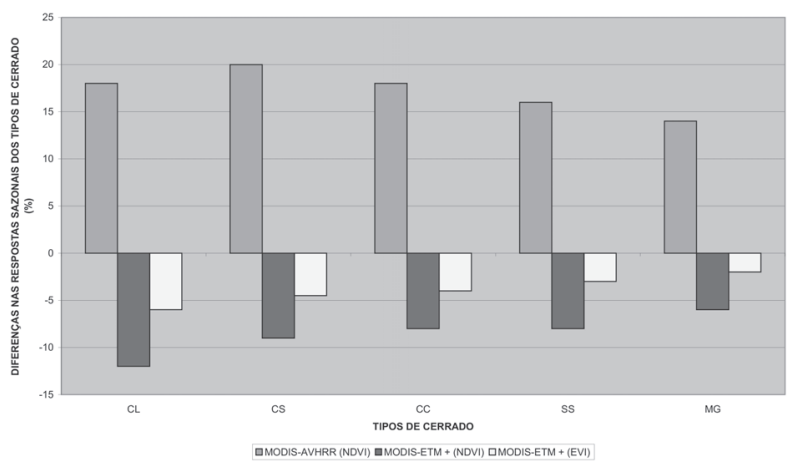

Figura 8 - Diferenças relativas nas respostas sazonais dos índices de vegetação MODIS e AVHRR e entre os índices MODIS e ETM+ (CL - Campo Limpo, CS - Campo Sujo, CC - Campo Cerrado, SS - Cerrado strictu sensu denso, MG - Mata de galeria) todo, de forma rotineira, com qualidade padronizada, e num nível de detalhe e freqüência que permita não só controlar o uso sustentável de toda a Amazônia como modelar tendências espaciais e temporais.

As respostas a essas questões têm implicações não apenas locais, mas também regionais e globais, no tocante ao funcionamento de outros sistemas ambientais, portando impactos sobre a biodiversidade, o ciclo hidrológico, os ciclos biogeoquímicos e sobre o clima do planeta Terra.

Os dados de sensoriamento remoto, aplicados em múltiplas escalas espaciais e temporais, representam o meio mais viável para o mapeamento do impacto humano na região Amazônica. Entretanto, para que o seu uso seja efetivo, é vital que os métodos de extração de informações sejam padronizados de tal modo que dados produzidos por diferentes grupos de pesquisa, em diferentes regiões, com diferentes produtos sejam comparáveis, e passíveis de integração numa mesma base de referência.

Com esse objetivo em mente Roberts (2002) propôs uma abordagem padrão, que envolve desde a retificação geométrica dos dados para uma base comum, à intercalibração das imagens para minimizar diferenças radiométricas derivadas do uso de diferentes tipos de sensores, da modificação da geometria de aquisição ao longo do ano e mudanças na composição da atmosfera. A partir da retificação geométrica e radiométrica das imagens, o passo lógico é a decomposição da informação radiométrica (energia refletida pela superfície em diferentes regiões do espectro) contida em cada elemento de resolução, em proporções de vegetação verde, vegetação fotossinteticamente não-ativa, sombra e solo. Essa decomposição é feita a partir de métodos de análise de mistura espectral.

As proporções resultantes da análise de mistura são usadas então para mapear florestas, pastos, vegetação secundária, culturas, solo preparado e áreas urbanizadas. A transição entre a classe floresta e as classes "não-floresta" são utilizadas para estimar as taxas de desmatamento e para mapear a estrutura de idade
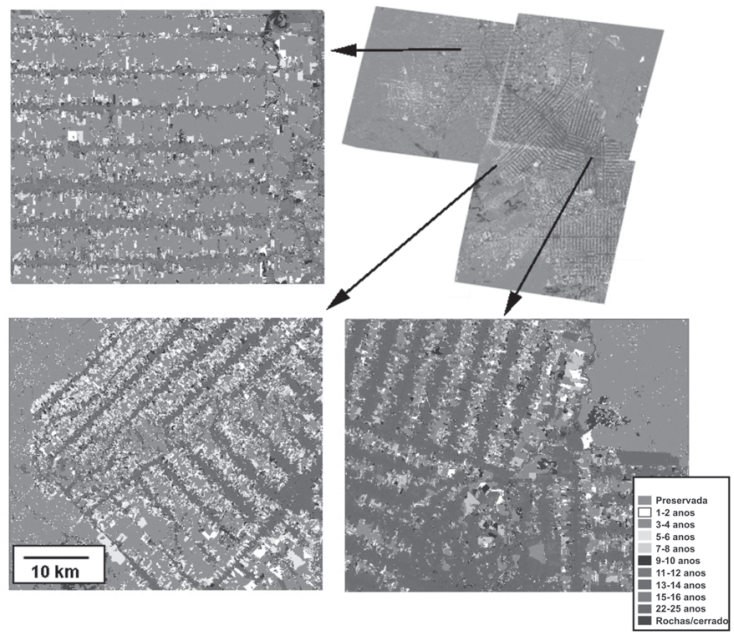

Figura 9 - Idade do Desflorestamento (Fonte: Roberts, 2002). 


\section{ACTA \\ AMAZONICA}

TÉCNICAS AVANÇADAS DE SENSORIAMENTO REMOTO APLICADAS AO ESTUDO DE MUDANÇAS CLIMÁTICAS E AO FUNCIONAMENTO DOS ECOSSISTEMAS AMAZÔNICOS das áreas não florestadas. As modificações na estrutura da floresta resultantes da degradação via fogo ou corte seletivo são mapeadas numa escala intra-pixel através da análise das mudanças na fração de sombra, vegetação fotossinteticamente não ativa, vegetação verde e solo.

Este tipo de abordagem facilita a análise de dados temporais porque padroniza os dados de entrada através de um conjunto de regras de decisão que são aplicadas a séries completas de dados sobre uma dada região. Novos conjuntos de dados podem, portanto, ser incorporados à análise na medida em que se tornem disponíveis, sem que todo o procedimento inicial tenha que ser refeito. Além disso, um aspecto relevante, é que as proporções de componentes de um pixel têm um significado físico que pode ser associado facilmente à realidade observada na natureza.

Essa abordagem foi aplicada com bastante êxito na Amazônia Central, no sudoeste da Amazônia (Rondônia) e na Amazônia Oriental (Marabá e Paragominas). Ela é ilustrada através de um estudo em que são utilizadas imagens MSS e TM Landsat adquiridas durante um período de vinte e cinco anos para mapear a idade das áreas desmatadas (Figura 9). Sua análise permite verificar que todas as classes etárias estão presentes em todos os municípios, mas que no Município de Ariquemes há uma concentração de novos assentamentos, sem que haja expansão nos assentamentos mais antigos.

Os resultados alcançados por Roberts (2002) indicam que para uma região com as dimensões da Amazônia é crítico o uso de uma metodologia padronizada. A vantagem de uma

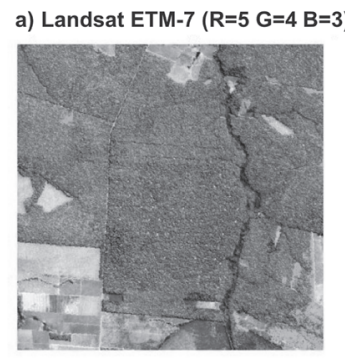

c) Imagem Fração Solo
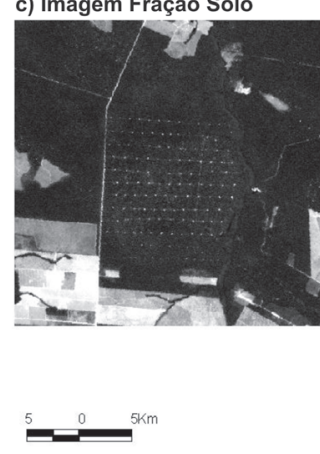

b) Landsat ETM-7 banda 3

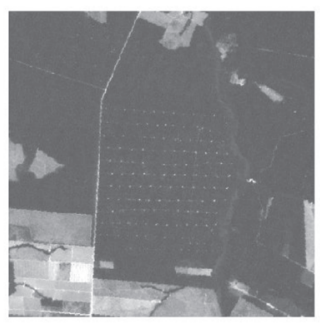

d) Imagem Classific ada

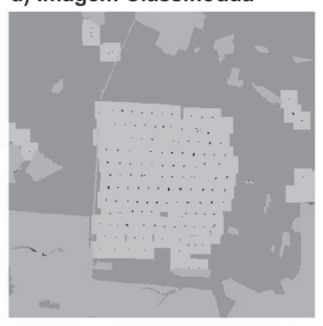

Floresta

Nãofloresta

Água

Derrubadas

Corte seletivo

recente
Figura 10 - Classificação de áreas sujeitas a corte seletivo (verde floresta; rosa- não floresta, azul- água, preto - áreas de retirada de árvores. Ocre- áreas de corte seletivo recente). (Fonte: Roberts, 2002). abordagem como esta é que ela permite comparar áreas com características ambientais diferentes bem como acompanhar mudanças de cobertura da terra ao longo de um grande período de tempo. Um dos resultados mais significativos do uso do modelo de mistura espectral é a sua capacidade de tornar mapeável, mudanças sutis na cobertura do solo como aquelas provocadas pelo corte seletivo, como pode ser observado na Figura 10.

\section{CONSIDERAÇÕES FINAIS}

Os trabalhos aqui apresentados demonstram o potencial dos dados de sensoriamento remoto e das técnicas de extração de informação para o monitoramento da dinâmica espaçotemporal da cobertura da vegetação, bem como para a identificação e parametrização de processos ecológicos em escala regional, como é o caso, das estimativas dos fluxos de carbono de áreas alagáveis.

Por outro lado, a parametrização de processos ecológicos requer abordagens cada vez mais quantitativas e dados orbitais com maior acuidade e precisão geométrica e radiométricas. Neste sentido, a diversidade de fontes de informação de sensoriamento remoto, também exige que o usuário da informação amplie seu conhecimento teórico sobre os limites da tecnologia de sensoriamento remoto.

Conforme discutido em um dos estudos apresentados neste artigo, muitos dos dados de sensoriamento remoto, encontram-se já disponibilizados no formato de medidas biofísicas as quais podem ser rapidamente assimiladas em modelos ecológicos. O uso desses produtos, entretanto, deve ser criterioso, uma vez que sua produção se baseia em um conjunto de pressupostos teóricos, os quais precisam ser conhecidos, para que a aplicação se torne eficiente.

Entretanto existem alguns desafios à frente, dentre os quais a ampliação da capacidade de Integrar imagens de diferentes resoluções e características radiométricas.

Outro aspecto importante a ser investigado é o da extrapolação de processos identificados a partir de escalas locais para as escalas de observação providas pelos dados de sensoriamento remoto (scaling up). Paralelamente um maior esforço teórico deve ser endereçado à vinculação entre padrões e processos em diferentes escalas.

Por último, mas não menos importante, há uma urgente necessidade de uniformização de linguagem e protocolos no âmbito da comunidade de sensoriamento remoto, para que a comunicação, difusão e troca de informações e idéias se tornem mais profícua.

\section{BIBLIOGRAFIA CITADA}

Barbosa, R. I. 1998. Avaliação da área dos sistemas naturais e agroecossistemas atingida pelo fogo no Estado de Roraima (01.12.1997 a 30.04.1998). Relatório Técnico INPA/ Roraima, Boa Vista. 15.p (http://agroeco.inpa.gov.br/reinaldo/ RIBarbosa_ProdCient_Usu_Visitantes/1998RelatFogo_1.pdf) 


\section{ACTA AMAZONICA}

Barbosa, C. C. F.; Hess, L; Melack, J; novo, E.M.L.M . 2000 Mapping Amazon Basin Wetlands Through Region Growing Segmentation and Segmented-Based Classification JERS-1 Data. In: IX Latin-American Symposium on Remote Sensing, 2000, Misiones, Argentina. Proceedings of the IX LatinAmerican Symposium on Remote Sensing held at Universidad Nacional de Lujan, Misiones, Argentina, 19-21 November, 2000, p. 131-139.

Câmara, G.; Souza, R.C.M.; Freitas, U.M.; Garrido, J.C.P. 1996. SPRING: Integrating remote sensing and GIS by objectoriented data modelling. Comput. Graph. 20: 395-403.

CPTEC. 2005. (http://www.cptec.inpe.br/enos/)

Chapman, B.; Siqueira, P.; Freeman, A. 2002. The JERS Amazon Multi-Season Mapping Study (JAMMS): observation strategies and data characteristics. Int. J. Remote Sens., 23:1427-1446.

Devol, A.H.; Richey, J.E.; Forsberg, B.R.; Martinelli, L.A. 1990. Seasonal dynamics in methane emissions from the Amazon River floodplain to the troposphere. J. Geophys.Res, 95: 16417-16426.

Ferreira Junior, L. G.; Yoshioka, H.; Huete, A. R.; Sano, E. E.,2004, Optical characterization of the Brazilian Savanna physiognomies for improved land cover monitoring of the Cerrado biome: preliminary assessments from an airborne campaign over an LBA core site. Journal of Arid Environments, 56(3): 425-447.

Ferreira Júnior, L.G.; Yoshioka, H.; Huete, A.R.; Sano, E.E. 2003. Seasonal landscape and spectral vegetation index dynamics in the Brazilian Cerrado: An analysis within the Large Scale Biosphere-Atmosphere Experiment in Amazônia (LBA). Remote Sensing of Environment (in press). 87: 534-550.

Ferreira Júnior, L. G.; Yoshioka, H.; Huete, A. R.; Shimabukuro, Y. .2000, The response of MODIS vegetation indices to the Brazilian Cerrado seasonal contrast: An analysis within the Large Scale Biosphere-Atmosphere Experiment in Amazonia (LBA). In: American Geophysical Union - Fall Meeting, 2000, San Francisco. EOS, Transactions, American Geophysical Union, 81: 207-207.

Hess, L.L.; Melack, J.M.; Simonett, D.S. 1990. Radar detection of flooding beneath the forest canopy: a review. Int. J. Remote Sens. 11: 1313-1325.

Hess, L.L.; Melack, J.M., Filoso, S.; Wang, Y. 1995. Delineation of inundated área and vegetation along the Amazon floodplain with the SIR-C synthetic aperture radar. IEEE Trans. Geosci. Remote Sens, 33: 896-904.

Hess, L.L.; Novo, E.M.L.M.; Slaymaker, D.M.; Holt, J.; Steffen, C.; Valeriano, D.M.; Mertes; L.A.K.; Krug, T.; Melack, J.M.; Gastil, M.; Holmes, C.; Hayward, C. 2002. Geocoded digital videography for validation of land cover mapping in the Amazon basin. Int. J.Remote Sens. 23: 1527-1555.

Hess, L.L; Melack, J.M.; Novo, E.M.L.M; Barbosa, C.C.F.; Gastil, M. 2003. Dual-Season Mapping of Wetland Inundation and Vegetation for the Central Amazon Basin. Remote Sensing of Environment, 87: 404-428.

Huete,A.; Ratana, P.; Ferreira, L.; Shimabukuro, Y.E.; Didan, K.; Miura,T, M. A. 2002. Look at Amazon Basin Seasonal Dynamics with the Biophysical Products from the Terra-
MODIS Sensor . 2nd International LBA Scientific Conference Manaus, Amazonas, Brazil, July 7-10.

Huete, A.; Didan, K.; Miura, T.; Rodriguez, E.; Xiang, G.; Ferreira, L.G. 2002a. Overview of the radiometric and biophysical performance of the MODIS vegetation indices. Remote Sensing of Environment, 83:195-213.

Justice, D.; Hall, V.; Salomonson, J.; Privette, G.; Riggs, A.; Strahler, W.; Lucht, R.; Myneni, Y.;Knjazihhin; S. Running; R. Nemani; E. Vermote, J.; Townshend, R.; Defries, D.; Roy, Z. ;Wan, A.; Huete, W. van Leeuwen, R. ;Wolfe, L.; Giglio, JP.; Muller, P.; Lewis, M. Barnsley .1998. The Moderate Resolution Imaging Spectroradiometer (MODIS): land remote sensing for global change research, IEEE Trans. on Geosci. and Remote Sensing, 36:1228-1249.

Mantovani, J.E.; Pereira, A. ,1998, Estimativa da integridade da cobertura de vegetação do Cerrado através de dados Landsat - TM. In: Simposio Brasileiro de Sensoriamento Remoto, 9, Santos, SP (versão em CD-ROM).

Melack, J.M.; Hess, L.L.; Sippel, S. 1994. Remote sensing of lakes and floodplains in theAmazon Basin. Remote Sens. Rev., 10: 127-142.

Melack,J.M; Forsberg, B. 2001. Biogeochemistry of Amazon floodplain lakes and associated wetlands. In: McClain ME,Victoria RL, Richey JE. The Biogeochemistry of the Amazon Basin and its Role in a Changing World (eds.) Oxford University Press, Oxford. p. 235-276.

Melack, J. M.; Hess, L. L.; Gastil, M.; Forsberg, B. R.; Hamilton, S.K.; Lima, I. B.T.; Novo, E. M.L.M. 2003. Regionalization of Methane Emissions in the Amazon Basin with Microwave Remote Sensing, Global Change Biology, (in press)

Myers, N. et al 2000. Biodiversity hotspots for conservation priorities. Nature, 403: 853 - 858 .

Myneni, R.B.; Hoffman, S.; Knyazikhin, Y.; Privette, J. L.; Glassy, J.; Tian, Y.; Y. Wang, X. Song, Y. Zhang, G. R. Smith et al. 2002. Global products of vegetation leaf área and fraction absorbed PAR from year one of MODIS data. Remote Sensing of Environment, 83:214-231.

Negreiros, G.H.; Nepstad, D.C; Sandberg, D.; Alvarado, E.; Hinckley, T.; Pereira, M. Fire along the Transition between the Amazon Forest and the Cerrado Ecosystem. Artigo apresentado na $13^{\text {th }}$ Conference on Fire and Forest Meteorology, 27-31 de Outubro, 1996 Lorne, Austrália.

Potter, C.; Randerson, J. T.; Field, C.B.; Matson, P.A.; Vitousek, P.M.; Mooney, H. A.; Klooster, S. A. 1993. Terrestrual ecosystem production: a process model based on global satellite and surface data. Global Biogechem. Cycles 7 (4): 811-841.

Potter, C.; Klooster, S. A; Brooks, V. 1999. Interannual variabilility in terrestrial net primary production: exploration of trends and controls on regional to global scales. Ecosystem 2(1): 36-48.

Potter C, Davidson EA, Nepstad D, de Carvalho CR. 2001. Ecosystem modeling and dynamic effects of deforestation on trace gas fluxes in Amazon tropical forests. Forest Ecology and Management, 152: 97-117. 
Potter, C. 2002. Understanding global teleconnections of climate to regional satellite observations for Amazon ecosystem processes. 2nd International LBA Scientific Conference Manaus, Amazonas, Brazil, July 7-10.

Richey, J.E., Melack, J.M., Aufdenkampe, A.K., Ballester, V.M. and Hess,L.L. 2002. Outgassing from Amazonian rivers and wetlands as a large tropical source of atmospheric CO2. Nature, 416: 617-620.

Roberts, D. 2002. Standardized remote sensing methodology for land-cover mapping in support of LBA. 2nd International LBA Scientific Conference ,Manaus, Amazonas, Brazil, July 7-10 .

Rosenqvist, A., Shimada, M., Chapman, B., Freeman, A. 2000. The Global RainForest Mapping project - a review. Int. J. Remote Sens., 21: 1375-1387.

Running, S.W., Justice, C., Salomonson, V., Hall, D., Barker, J., Kaufman, Y.,Strahler, A., Huete, A., Muller, J.P., Vanderbilt, V., Wan, Z.M., Teillet, P., Carneggie,D. 1994. Terrestrial remote sensing science and algorithms planned for EOS/ MODIS Int. J. of Remote Sensing 15:3587-3620.

Sano, E. E., Barcellos, A. O., Bezerra, H. S. 2001,Assessing the spatial distribution of cultivated pastures in the Brazilian savanna. Pasturas Tropicales, 22 (3): 2-15.
Shimabukuro, Y. E.; Novo, E.M.L.de M.; Santos, J. R.; Krug,T.; Hess, L.L. 1999. Estimativa da area de cobertura florestal afetada pelo incendio em Roraima, utilizando dados multisensores São José dos Campos. INPE-7119-RPQ/697 Relatório Técnico (Divisão de Sensoriamento Remoto Instituto Nacional de Pesquisas Espaciais.

Sippel, S.J.; Hamilton, S.K.; Melack, J.M.; Novo, E.M.M. 1998. Passive microwave observations of inundation area and the area/stage relation in the Amazon River floodplain. Int. J. Remote Sens., 19: 3055-3074.

Skole, D.L.; Chomentowiski, W.H.; Salas, W.A.; Nobre, C.A. 1994. Physical and human dimensions of deforestation in Amazonia. Biosciences, 44: 314-322.

Vermote, E.; El Saleous, N.; Justice, C. 2002. Atmospheric correction of the MODIS data in the visible to middle infrared: First results. Remote Sens. Environ, 83:97-111.

\section{RECEBIDO EM 04/07/2003 ACEITO EM 04/04/2004}

